\title{
Semiannual and annual variations in the height of the ionospheric F2-peak
}

\author{
H. Rishbeth ${ }^{1}$, K. J. F. Sedgemore-Schulthess ${ }^{1}$, T. Ulich $^{2}$ \\ ${ }^{1}$ Department of Physics and Astronomy, University of Southampton, Southampton SO17 1BJ, UK \\ ${ }^{2}$ Sodankylä Geophysical Observatory, Tähteläntie 112, Sodankylä FIN-90570 Finland
}

Received: 12 July 1999 / Revised: 22 November 1999 / Accepted: 3 December 1999

\begin{abstract}
Ionosonde data from sixteen stations are used to study the semiannual and annual variations in the height of the ionospheric F2-peak, $h \mathrm{mF}$ 2. The semiannual variation, which peaks shortly after equinox, has an amplitude of about $8 \mathrm{~km}$ at an average level of solar activity (10.7 cm flux $=140$ units), both at noon and midnight. The annual variation has an amplitude of about $11 \mathrm{~km}$ at northern midlatitudes, peaking in early summer; and is larger at southern stations, where it peaks in late summer. Both annual and semiannual amplitudes increase with increasing solar activity by day, but not at night. The semiannual variation in $h \mathrm{mF} 2$ is unrelated to the semiannual variation of the peak electron density $N \mathrm{mF} 2$, and is not reproduced by the CTIP and TIME-GCM computational models of the quiet-day thermosphere and ionosphere. The semiannual variation in $h \mathrm{mF} 2$ is approximately "isobaric", in that its amplitude corresponds quite well to the semiannual variation in the height of fixed pressure-levels in the thermosphere, as represented by the MSIS empirical model. The annual variation is not "isobaric". The annual mean of $h \mathrm{mF} 2$ increases with solar $10.7 \mathrm{~cm}$ flux, both by night and by day, on average by about $0.45 \mathrm{~km} /$ flux unit, rather smaller than the corresponding increase of height of constant pressure-levels in the MSIS model. The discrepancy may be due to solar-cycle variations of thermospheric winds. Although geomagnetic activity, which affects thermospheric density and temperature and therefore $h \mathrm{mF} 2$ also, is greatest at the equinoxes, this seems to account for less than half the semiannual variation of $h \mathrm{mF} 2$. The rest may be due to a semiannual variation of tidal and wave energy transmitted to the thermosphere from lower levels in the atmosphere.
\end{abstract}

Key words: Atmospheric composition and structure (thermosphere - composition and chemistry) Ionosphere (mid-latitude ionosphere)

Correspondence to: $\mathrm{H}$. Rishbeth

\section{Introduction}

Several atmospheric, ionospheric and geomagnetic parameters display a regular semiannual (6-monthly) variation, with maxima near the March and September equinoxes. They include the peak electron density of the ionospheric F2-layer $(\mathrm{NmF} 2)$ in some parts of the world (Burkard, 1951; Yonezawa and Arima, 1959; Chaman Lal, 1992); the height of the F2-layer peak $(h \mathrm{mF} 2)$ (Becker, 1967); the neutral air density $\rho$ in the thermosphere (Paetzold and Zschörner, 1961); and geomagnetic indices such as Kp and Ap (Bartels, 1963; Green, 1984). Semiannual oscillations also exist in the lower and middle atmosphere. Annual (12-monthly) variations also exist in $h \mathrm{mF} 2$ and $\rho$, with maxima usually in summer. The case of noon NmF2 is complicated: in some parts of the world its predominant variation is semiannual, but elsewhere it is annual, usually with a winter maximum (e.g. Yonezawa and Arima, 1959; Yonezawa, 1971; Torr and Torr, 1973).

Most of these annual and semiannual phenomena have been extensively studied. An exception is the semiannual variation in $h \mathrm{mF} 2$, which does not seem to have received much discussion since Becker's (1964, 1967) papers thirty years ago. Figure 1 shows the 27 -day running mean of noon $h \mathrm{mF} 2$ for a twelve month period in 1963-1964 at Lindau, Germany, derived by real height $N(\mathrm{~h})$ analysis of ionograms by Becker (1967). The day-to-day variability of $h \mathrm{mF} 2$ has been considerably smoothed by the 27-day averaging (judging from Becker's daily values during this period which are shown in Fig. 5 of Rawer, 1969). Also plotted in Fig. 1 is the average month-by-month variation of the magnetic parameter $A \mathrm{p}$, which shows the equinox peaks in magnetic activity, the influence of which is discussed in Sect. 4.2 (the September peak is influenced by an immense storm, with $A \mathrm{p}=126$ on 22 September, 1963). During these 12 months, the solar $10.7 \mathrm{~cm}$ radio flux $F_{10.7}$ (used as a conventional indicator of solar activity) was fairly steady, in the range 75-90 flux units, except in late 

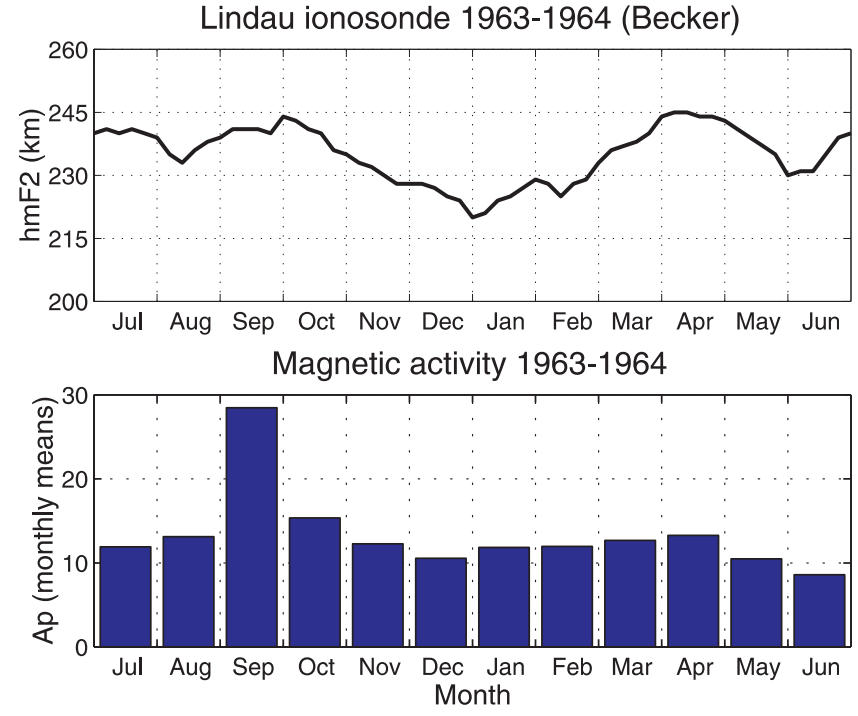

Fig. 1. Plot of $h \mathrm{mF} 2$ at Lindau $\left(52^{\circ} \mathrm{N}\right)$, as derived from ionograms by Becker (1967), and the geomagnetic index $A \mathrm{p}$ for the 12-month period July 1963 to June 1964

September 1963 when it rose to around 100 units. The semiannual variation is not so consistent or well-defined for the period 1957-1958. The dependence on $F_{10.7}$ of day-to-day values of $h \mathrm{mF} 2$ is not clear-cut, in that the Lindau data for 1958 show a great deal of scatter when plotted against $F_{10.7}$ (Becker, 1964). Eccles et al. (1967) commented on Becker's results, but they could only reproduce a semiannual variation of $h \mathrm{mF} 2$ by the device of imposing a semiannual temperature variation in their model.

Further investigation of $h \mathrm{mF} 2$ is required. Concentrating on midday and midnight, we tackle the question in two ways: in Sect. 2 by Fourier analysis of $h \mathrm{mF} 2$ data from several ionosonde stations over three solar cycles, and in Sect. 3 by using the global thermospheric models TIME-GCM (Roble et al., 1988) and CTIP (FullerRowell et al., 1996; Millward et al., 1996a). In Sect. 4 we investigate whether the variations of $h \mathrm{mF} 2$ are "isobaric", by comparing them with the variations in height of fixed pressure-levels in the thermosphere, as expressed by the MSISE-90 thermospheric model. We also estimate the effect on $h \mathrm{mF} 2$ of geomagnetic activity, in particular the equinoctial peaks in $A$ p. In Sect. 5 we review possible causes of the semiannual variation of $h \mathrm{mF} 2$.

\section{Values of $h \mathrm{mF} 2$ derived from ionosonde data}

\subsection{Analysis}

Our data comprise values of $h \mathrm{mF} 2$ for sixteen stations (Table 1a, b). The values of $h \mathrm{mF} 2$ were derived from "MUF factors" (M3000) tabulated in ionosonde data taken from the National Geophysical Data Centre Vertical Sounding Database, using the formulae proposed by Shimazaki (1955) and Bilitza et al. (1979). M3000 is the factor which, in theory, relates the maximum usable frequency for propagation over a $3000 \mathrm{~km}$ path to the ordinary critical frequency $f_{\mathrm{oF}} 2$. According to the "Shimazaki formula", which assumes the idealized case of radio waves reflected from a parabolic F2 layer above a spherical Earth:

$h \mathrm{mF} 2=\{1490 / M 3000\}-176[\mathrm{~km}]$

The "Bilitza formula", which allows for the effect of ionization below the F2-layer, takes the form

$h \mathrm{mF} 2=\{1490 /(M 3000+\Delta M(X))\}-176[\mathrm{~km}]$

where $\Delta M(X)$ is an empirical function of the critical frequency ratio $X=f_{\mathrm{oF}} 2 / f_{\mathrm{oE}}$, taking account of sunspot number and geomagnetic latitude. The correction is important by day, as we show later, but is sufficiently small at night for the plain "Shimazaki formula" Eq. (1a) to be used. The formulas are unreliable if $M 3000$ is small, i.e. the layer is high, or if $f_{\mathrm{OF}} 2$ is too close to $f_{\mathrm{oE}}$ (e.g. Dudeney, 1983). Ulich and Turunen (1997) find that the Bilitza formula overestimates daytime $h \mathrm{mF} 2$, on average by $18 \mathrm{~km}$, as compared to the value found from real height inversion (using the polynomial method of Titheridge, 1969). As the error depends on $X$ and increases when $X$ is large (McNamara et al., 1987), as at solar maximum, it may affect our results for the solar cycle variations of $h \mathrm{mF} 2$.

It is most desirable to use data that are consistently scaled and well-calibrated across any changes of instrument and site. Several stations that we used meet this criterion, but not necessarily for the whole period 1957 1994 spanned by our data. To increase confidence in the analysis, we imposed the conditions $M 3000>2.5$ and $X>1.7$, which limited the number of stations for which we had MUF data of acceptable quality, especially at night. Only a few stations in the Southern Hemisphere met the criteria, and we omitted stations near the magnetic equator, because of doubts about the reliability of any MUF-based formula. We use monthly medians, averaging the daytime values of $h \mathrm{mF} 2$ over the period 10-14 LT and the nighttime values over $22-$ 02 LT. Our analysis program makes a linear interpolation through data gaps of up to three months while rejecting data containing longer gaps; for most stations, we have useful results for 25-30 years. As magnetic activity is enhanced at the equinoxes, the median values for equinox months correspond to higher levels of $A \mathrm{p}$ than do those for solstice months; in Sect. 4.2 we discuss the possible effect of this on our results.

\subsection{Annual means of $h m F 2$}

The month-by-month data for sixteen stations are shown in Fig. 2. At all these stations, $h \mathrm{mF} 2$ is clearly higher at night than by day, and the day and night plots clash only at Kerguelen. Perusal of the plots shows an overlying solar-cycle variation everywhere, with marked station-to-station differences in annual and semiannual variations. For example, by day the annual variations are especially strong at Port Stanley, and at Moscow the semiannual variation has noticeably higher peaks in 
Table 1. a Height $h \mathrm{mF} 2$ at midday (10-14 LT) for solar flux $F_{10.7}$ $=140$ units, computed from ionosonde "MUF" data; $h_{0}$ is the annual mean, $h_{0}^{\prime}$ is the rate of change $\mathrm{d} h_{0} / \mathrm{d} F_{10.7}$; the amplitudes $h_{1}$ and $h_{2}$ refer to the annual and semiannual components as defined in Eq. (2). Stations are arranged in order of magnetic invariant latitude. b. Height $h \mathrm{mF} 2$ at night (22-02 LT) for solar flux $F_{10.7}=$ 140 units, computed from ionosonde "MUF" data. Layout as for Table 1a

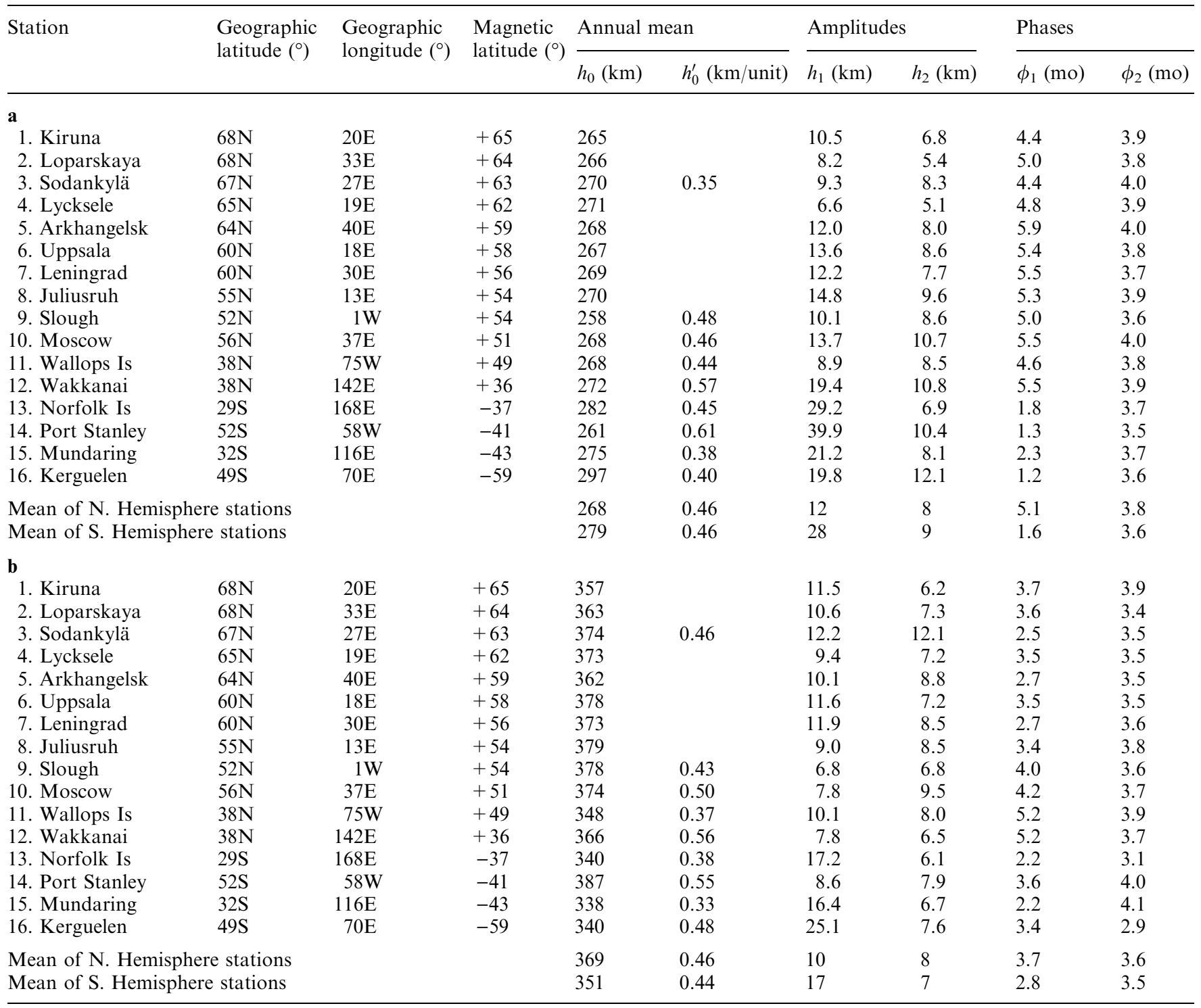

spring than in autumn. Table $1 \mathrm{a}, \mathrm{b}$ gives values of the annual mean $h_{0}$ for $F_{10.7}=140$, which represents a midway value between solar minimum $\left(F_{10.7} \approx 70\right)$ and the peak values of $F_{10.7}$ at the three solar maxima (232 in 1958, 156 in 1970, 203 in 1981 and 212 in 1989); 140 is also the value of $F_{10.7}$ used in the TIME-GCM runs (Sect. 3.1). The stations are arranged in order of decreasing magnetic latitude though, apart from Moscow and Port Stanley, the order would be unchanged if instead they were arranged geographically. The values of $h_{0}$ for the Northern Hemisphere stations are rather uniform, averaging $268 \mathrm{~km}$ by day and $369 \mathrm{~km}$ at night, with no clear latitude trend. The southern stations are less consistent, but on average $h \mathrm{mF} 2$ is higher by day $(279 \mathrm{~km})$ and lower at night $(351 \mathrm{~km})$ than in the Northern Hemisphere. The rate of increase with solar flux, $\mathrm{d} h_{0} / \mathrm{d} F_{10.7}$ (shown for a representative selection of stations), averages $0.44-0.46 \mathrm{~km} / \mathrm{unit}$ by day and night in both hemispheres. As mentioned in Sect. 2.1, the values of $\mathrm{d} h_{0} / \mathrm{d} F_{10.7}$ may be a little too large, the overestimate being perhaps $0.05 \mathrm{~km} /$ unit.

\subsection{Fourier analysis to derive annual and semiannual components}

For the Fourier analysis, we take twelve monthly data values for a given year and fit mean, annual and semiannual components, thus:

$$
\begin{aligned}
h \mathrm{mF} 2= & h_{0}+h_{1} \cos \left((\pi / 6)\left(t-\phi_{1}\right)\right) \\
& +h_{2} \cos \left((\pi / 3)\left(t-\phi_{2}\right)\right)
\end{aligned}
$$




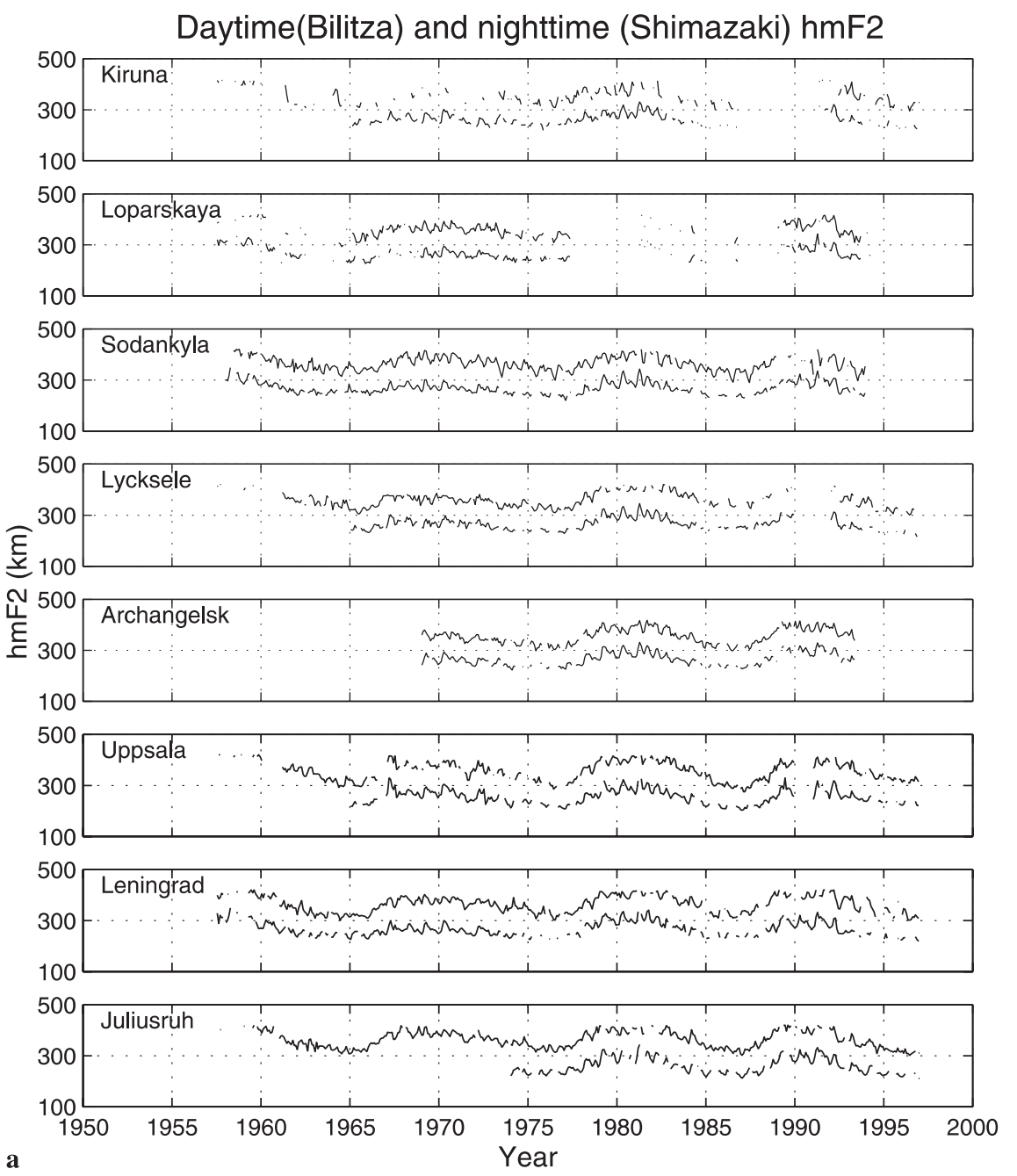

Fig. 2a, b. Time sequences of day (10-14 LT) (lower curve in each box) and night (22-02 LT) (upper curve in each box) values of $h \mathrm{mF}$, computed from tabulated MUF factors derived from ionograms, using monthly values for 16 stations arranged in order of decreasing magnetic latitude. a Kiruna to Juliusruh; b Slough to Kerguelen where the amplitudes $h_{0}, h_{1}, h_{2}$ are in kilometres, and time $t$ and the phases $\phi_{1}$ and $\phi_{2}$ are in months, zero phase being a maximum in mid-December. These phases, based on one-monthly data points, should be accurate to $1 / 2$ month or possibly slightly better.

Figure 3 shows the importance of the "M3000 correction" $\Delta M$ for underlying ionization, using two stations with very good datasets, Moscow and Sodankylä. The upper boxes show the annual and semiannual amplitudes $h_{1}$ and $h_{2}$ for daytime, derived by using the "Bilitza formula", Eq. (1b), which includes the correction; the lower boxes show the corresponding results given by the plain "Shimazaki formula", Eq. (1a), which does not. Applying the correction $\Delta M$ clearly makes a great difference to the annual amplitudes, but has much less effect on the semiannual amplitudes.

The reason is not far to seek. If $\Delta M$ is omitted or is incorrect, the computed annual component in $h \mathrm{mF} 2$ is strongly influenced by the F1-layer, which is most prominent in summer and usually absent in winter, as well as by the E-layer. As the critical frequencies $f_{\mathrm{OE}}$ and $f_{\mathrm{OF}} 1$ are closely controlled by the solar zenith angle, which is the same at both equinoxes, variations of the E- and F1-layers should not seriously affect the semiannual component.
Figure 4 shows periodograms for five of the stations, chosen to give a wide geographical spread. It is obvious that the relative strength of the annual and semiannual components may be quite different between day and night at one station, and also that it varies greatly between stations. Compare, for example, the almost pure annual variation at Port Stanley (day) to the predominantly semiannual variation at Moscow (night). With a data run of 30 years, as available at most of these stations, the resolution is of order $3 \%$ (or 0.4 month) for the annual variation and $1.5 \%$ (or 0.1 month) for the semiannual variation. Tests made for Sodankylä, using the polynomial method of Titheridge (1969) to compute real heights, give similar results but with a rather smaller semiannual/annual ratio than shown in Fig. 3.

\subsection{Annual and semiannual components: results}

Figure 5a for day and $5 \mathrm{~b}$ for night show the amplitudes $h_{0}, h_{1}, h_{2}$ plotted against the annual mean values of $F_{10.7}$ for the same five stations as used in Fig. 4, each point representing an individual year. The data points are well fitted by straight lines, with high correlation coefficients $r\left(h_{0}\right)$, both by day $(0.81-0.94)$ and at night $(0.75-0.92)$. 


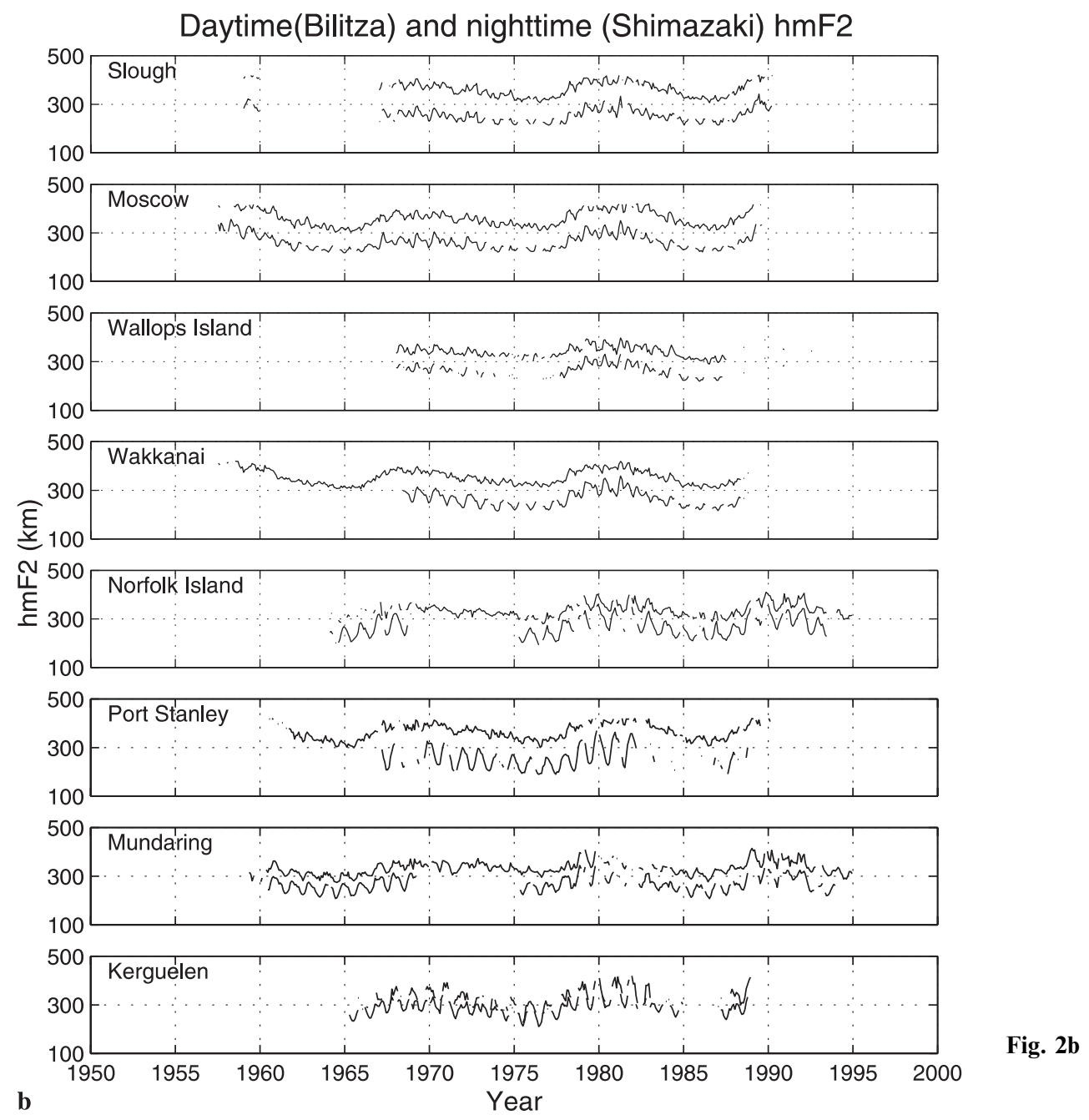

The 5\% significance levels ( 2 standard deviations) are in most cases $( \pm)$ 20-30 km.

The centre and right-hand boxes in Fig. $5 \mathrm{a}, \mathrm{b}$ show the plots of $h_{1}$ and $h_{2}$ versus $F_{10.7}$, also fitted with straight lines. These plots contain a great deal of scatter, but by day there is a clear upward trend. For northern stations the correlation coefficients $r\left(h_{1}\right)$ are in the range $0.35-0.8$ and $r\left(h_{2}\right)$ are in the range $0.4-0.7$, but the correlation coefficients are on the whole smaller at southern stations $(0.07-0.5)$. The rates of increase are such that, from solar minimum $\left(F_{10.7}=70\right)$ to solar maximum $\left(F_{10.7}=200\right)$, daytime $h_{1}$ increases on average by $10 \mathrm{~km}$ and daytime $h_{2}$ by $8 \mathrm{~km}$. At night the variations of $h_{1}$ and $h_{2}$ with $F_{10.7}$ are not significant; the correlation coefficients are small (mostly $<0.3$ ) and most are negative, implying a slight tendency for the amplitudes to decrease with increasing $F_{10.7}$. Numerical values of $h_{0}, h_{1}, h_{2}$ at $F_{10.7}=140$ for all sixteen stations are given in Table 1a for day and $1 \mathrm{~b}$ for night.

Port Stanley stands out from the other stations because of its very large day-to-night change in $h_{0}$ and its large daytime annual component $h_{1}$, which doubles in amplitude from solar minimum $(30 \mathrm{~km})$ to solar maximum $(60 \mathrm{~km})$. The low daytime $h_{0}$, high nighttime $h_{0}$, and large daytime amplitude $h_{1}$ at Port Stanley is seen also at number 14 in Fig. 6, which shows the Fourier results for all stations. A large daytime annual component $h_{1}$ is seen at the southern stations (13-16), and at Wakkanai in the Northern Hemisphere (12). Other notable features are the low daytime $h_{0}$ at Slough (9) and the low nighttime $h_{0}$ at Wallops Island (11).

As for phases, Table 1a shows that, at northern stations by day, the annual phase $\phi_{1}$ is in the range 4-6 months, corresponding to maximum in mid-April to mid-June, and in late summer (1-2 months) at the southern stations (13-16). The semiannual phase $\phi_{2}$ is consistently near equinox (3-4 months). At night, Table $1 \mathrm{~b}$ shows that the semiannual variation again has its maxima near equinox, but the annual phase is usually earlier than by day, the maximum being at $2-5$ months (February-May). We found no well-defined variation of the phases with $F_{10.7}$ though, at lower $F_{10.7}$, when the amplitudes are smaller and the phases are less well determined, there is more scatter, particularly in the annual component.

From the midlatitude results, in particular the consistent values of $\phi_{2}$, we conclude that the semiannual variation of noon $h \mathrm{mF} 2$ is real. Its amplitude $h_{2}$ is rather smaller than the annual amplitude $h_{1}$. The combination of the semiannual spring maximum and the early summer 

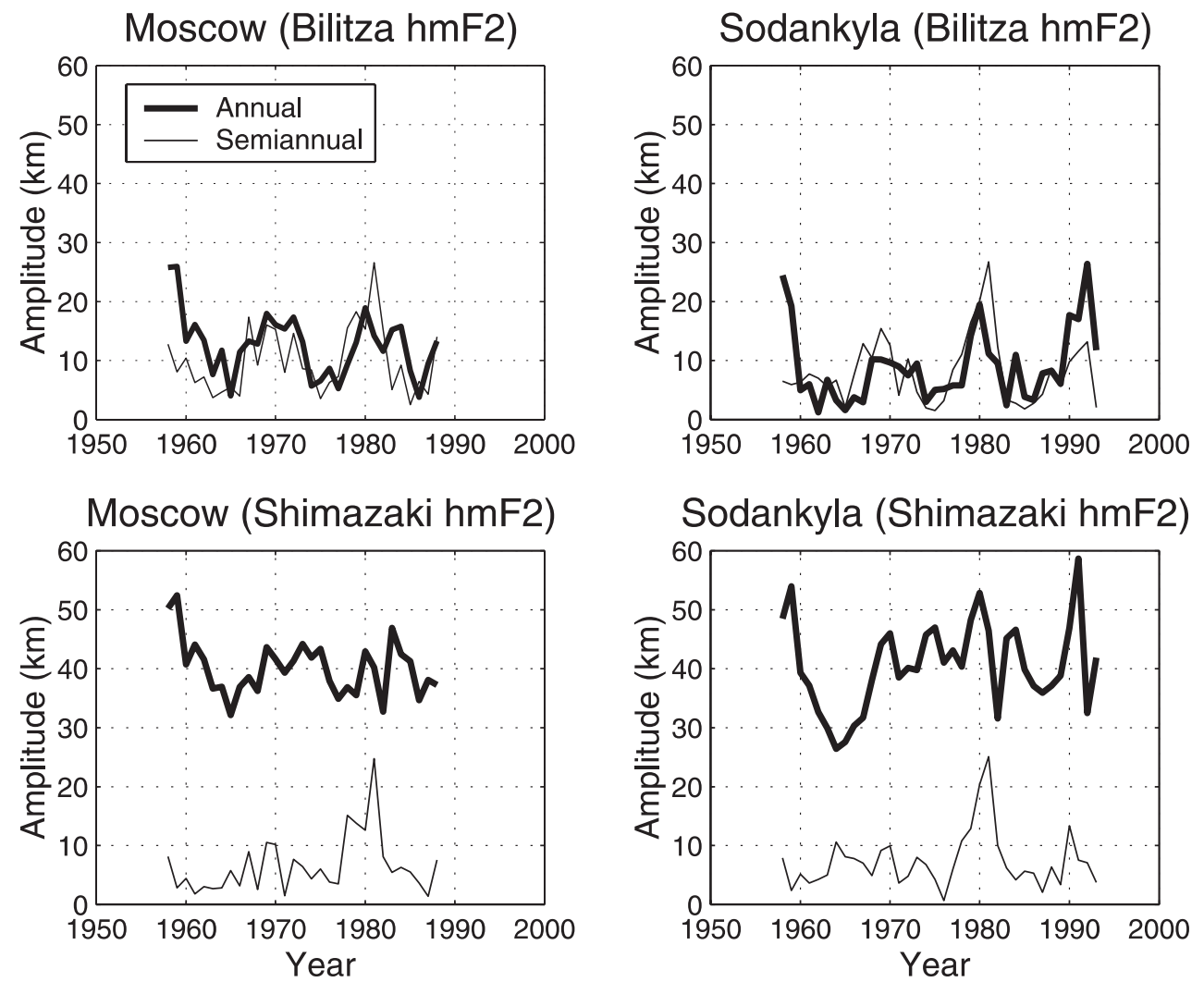

Fig. 3. Comparison of the amplitudes of the annual and semiannual components of $h \mathrm{mF} 2$, with ("Bilitza") and without ("Shimazaki") corrections for ionization underlying the F2-layer for day (10-14 LT)

maximum of the annual component produces an April or May maximum of noon $h \mathrm{mF} 2$ at northern stations; in the south, with a relatively small semiannual component, the maximum occurs in January or February.

\subsection{Incoherent scatter data on hmF2 at Millstone Hill}

We examined daytime values of $h \mathrm{mF} 2$ obtained in 1968 1971 from the incoherent scatter radar at Millstone Hill $\left(43^{\circ} \mathrm{N}\right)$, given by Papagiannis et al. (1975) in the following form:

$$
\begin{aligned}
& h \mathrm{mF} 2=280+9 K \mathrm{p}=304[\mathrm{~km}] \text { (summer) } \\
& h \mathrm{mF} 2=290+4 K \mathrm{p}=301[\mathrm{~km}] \text { (equinox) } \\
& h \mathrm{mF} 2=265+5 K \mathrm{p}=278[\mathrm{~km}] \text { (winter) }
\end{aligned}
$$

where the last value in each line is for $K \mathrm{p}=2.7$, the mean value for the years in question. In this period the average $F_{10.7}$ is 144 , so these values of $h \mathrm{mF} 2$ may reasonably be compared with the ionogram-derived values for $F_{10.7}=$ 140. Annual and semiannual amplitudes and phases cannot be determined from three values, but we can derive minimum amplitudes by assuming that the annual component maximizes in summer and the semiannual component at equinox. With these assumptions, the annual mean is $296 \mathrm{~km}$, the annual amplitude is $13 \mathrm{~km}$ and the semiannual amplitude is $10 \mathrm{~km}$, all of which are rather greater than the values derived from ionosonde data at northern stations (Table 1a). If the phases are not as assumed, the amplitudes will be greater.

\section{Modelling of $\boldsymbol{h m F 2}$ with global thermosphere-ionosphere models}

\subsection{Global modelling using TIME-GCM}

In Table 2 we show results obtained from the TIMEGCM Community Climate Model 3 for seven stations (which were chosen for another investigation, five of them being the same used in our data analysis); the values of $h \mathrm{mF} 2$ were kindly made available by R. G. Roble. For the simulation, solar activity is fixed at a moderate level $\left(F_{10.7}=140\right.$ flux units $)$ and magnetic conditions are quiet. We took smoothed daily values of $h \mathrm{mF} 2$ to represent day 16 of each month; the daytime results are for $12 \mathrm{LT}$, the nighttime results for $02 \mathrm{LT}$ (which, for our purposes, does not differ significantly from midnight).

Table 2 shows that $h \mathrm{mF} 2$ is consistently higher in summer than in winter, both by day and by night. By day, the amplitude $h_{1}$ is larger in the Southern than in the Northern Hemisphere, but not necessarily at night. In all cases the annual maximum occurs in local summer. The semiannual variation is barely significant, the amplitude $h_{2}$ being small compared to $h_{1}$ at all the stations, so the semiannual phase is poorly determined. As TIME-GCM uses a height step of $1 / 2$ scale height, corresponding to about $25 \mathrm{~km}$, the fitting procedure used to derive $h \mathrm{mF} 2$ should be accurate to one-third of a height step, and thus better than $10 \mathrm{~km}$, so the values of $h_{1}$ should be reliable even if those of $h_{2}$ are not. No relationship is found in the TIME-GCM results between the amplitudes of the semiannual variations of $h \mathrm{mF} 2$ and those of $N \mathrm{mF} 2$. 

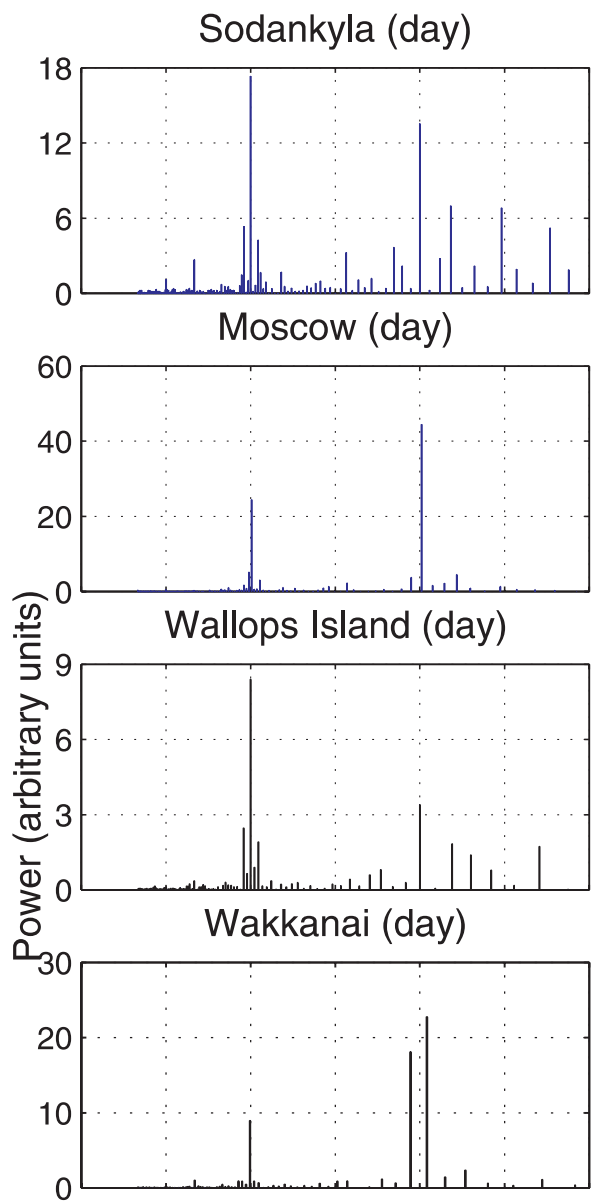

Port Stanley (day)

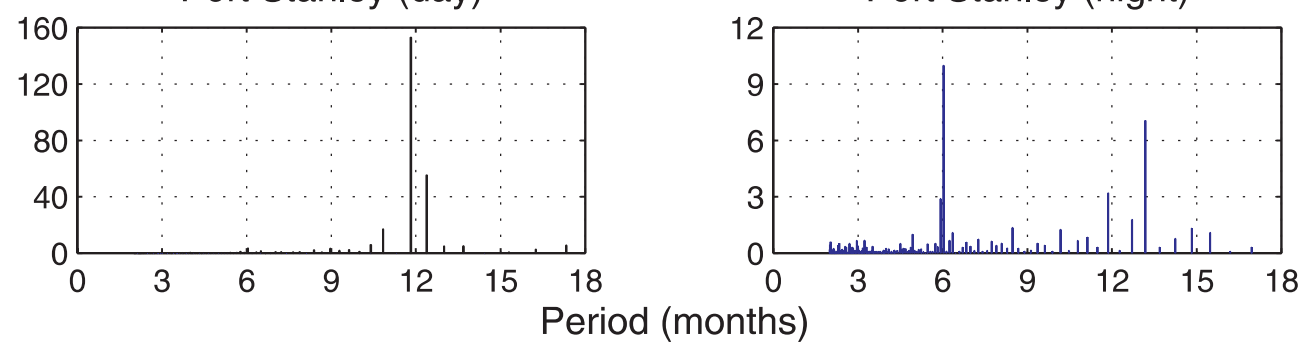

Sodankyla (night)
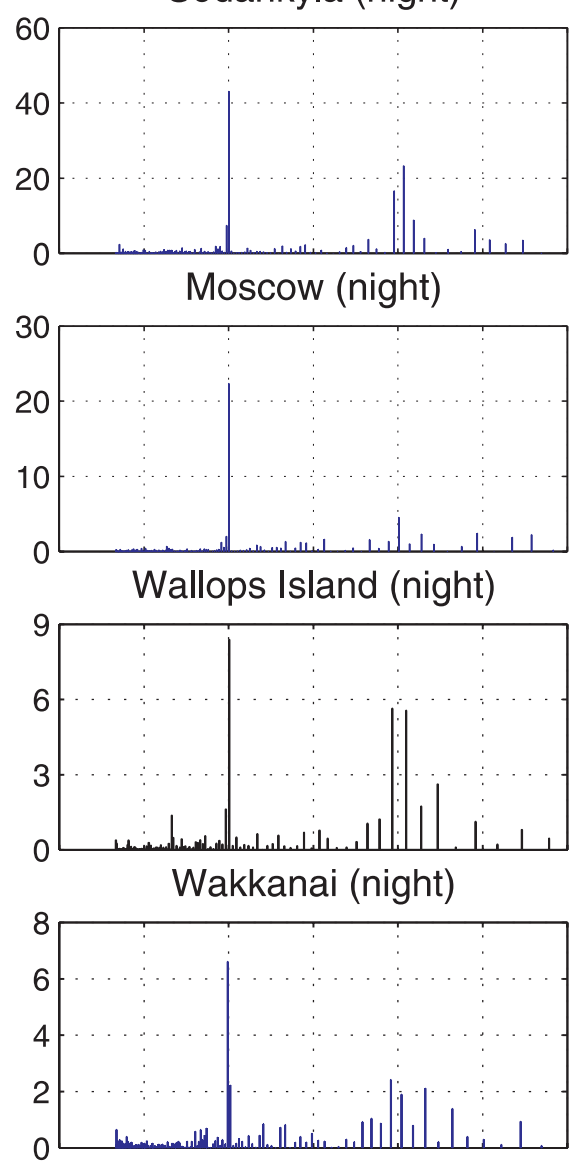

Port Stanley (night)

Fig. 4. Day (10-14 LT) and night (22-02 LT) periodograms of $h \mathrm{mF} 2$ for five stations

Table 2. Midday and night $h \mathrm{mF} 2$ : amplitudes and phases from TIME-GCM model, $F_{10.7}=140$

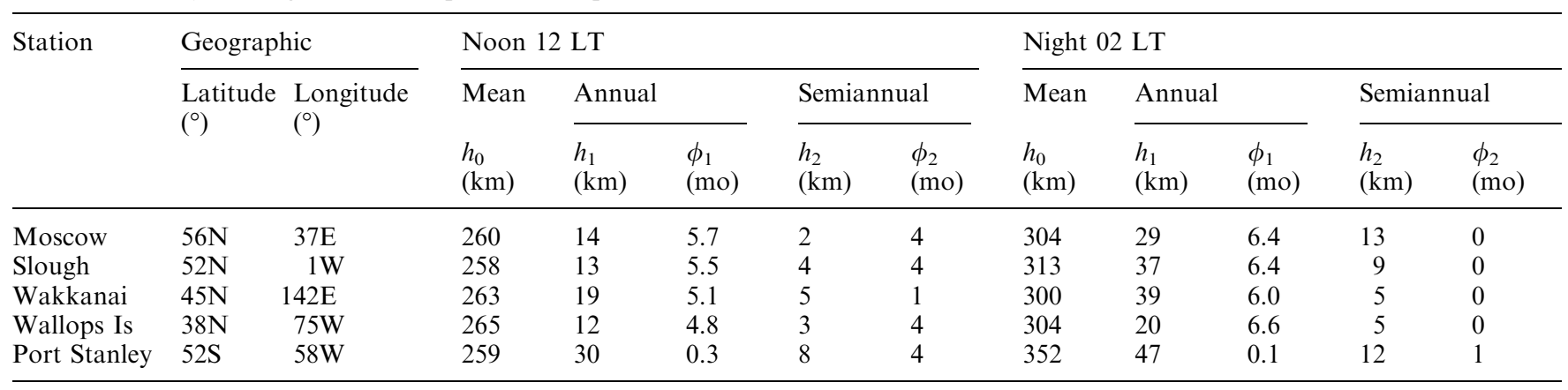

\subsection{Global modelling using CTIP}

The CTIP model was run as described by Zou et al. (2000), for each month of the year, assuming constant solar activity of $F_{10.7}=100$ units and quiet geomagnetic conditions $(K \mathrm{p}=2, A \mathrm{p}=7)$. At noon, the mean level $h_{0}$ is about $260 \mathrm{~km}$ at high midlatitudes but, below magnetic latitudes $\pm 25^{\circ}, h_{0}$ increases towards a value of about $360 \mathrm{~km}$ at the magnetic equator. With a computational height step of one scale height (typically $45 \mathrm{~km}$ ), 


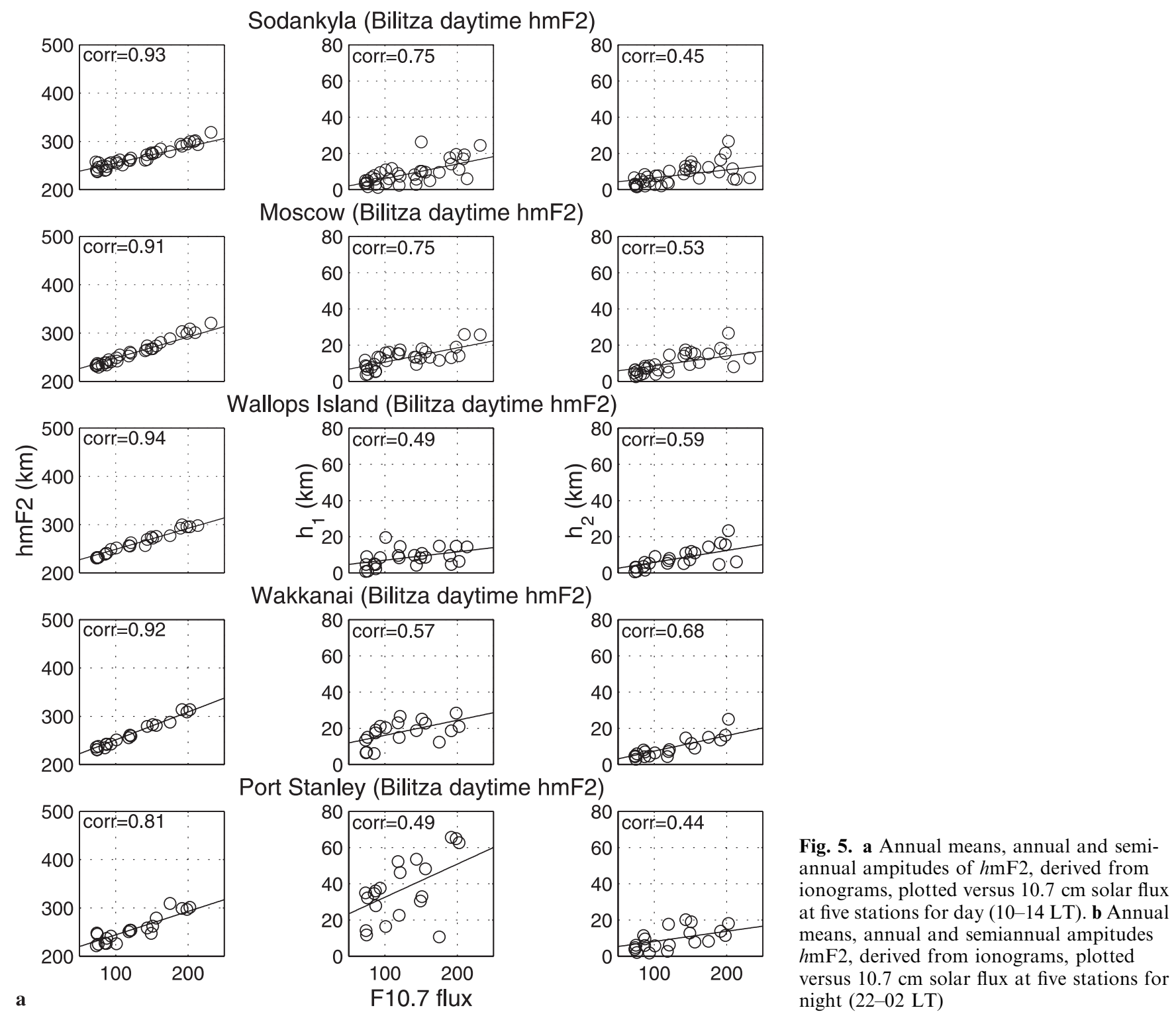

the accuracy of $h \mathrm{mF} 2$ is probably one-third of this, about $15 \mathrm{~km}$, so the amplitudes are not very accurately defined. The phases are accurate to within 1 month.

Omitting the equatorial zone within magnetic latitudes $\pm 25^{\circ}$, the Fourier components may be summarized as follows. At noon, the annual amplitude $h_{1}$ is about $15 \mathrm{~km}$ at northern midlatitudes. In the Southern Hemisphere $h_{1}$ varies with longitude, being about $15 \mathrm{~km}$ in western longitudes and $20-25 \mathrm{~km}$ in eastern longitudes. The phase $\phi_{1}$ corresponds closely to summer solstice, i.e. $0-1$ month in the southern magnetic hemisphere, 6 months in the north, the boundary being at the magnetic and not the geographic equator. The semiannual amplitude $h_{2}$ is very small $(<5 \mathrm{~km})$ at midlatitudes, with phase $\phi_{2} \approx 3$ corresponding to equinox. The results for midnight are broadly similar, except that the mean level is $310-360 \mathrm{~km}$ (varying with longitude); the semiannual component is slightly larger than by day, with $h_{2} \leq 10 \mathrm{~km}$ and maxima near solstice $\left(\phi_{2} \approx 0\right)$. The CTIP results for higher solar activity, $F_{10.7}=180$, show a similar distribution of annual and semiannual components, but with an amplitude ratio $h_{1} / h_{2}$ that is rather smaller (typically by about $30 \%$ ) than at $F_{10.7}=100$.

Comparing the CTIP and TIME-GCM results for the seven stations listed in Table 2, we find a great deal of similarity. Averaged over the seven stations, the mean values $h_{0}$ are about $5 \mathrm{~km}$ lower for CTIP than for TIME-GCM but about $12 \mathrm{~km}$ higher at night. The annual amplitude $h_{1}$ is in most cases smaller for CTIP than for TIME-GCM, notably at Port Stanley. The differences seem to be associated with the meridional winds, which are particularly strong in TIME-GCM in this sector, and are very dependent on the details of the neutral temperature and pressure distributions. The phase of the annual component of $h \mathrm{mF} 2$, with maximum in summer in both models, agrees with all the noon data and almost all the night data shown in Table 1a, b.

In both CTIP and TIME-GCM, most of the semiannual amplitudes $h_{2}$ are only a few kilometres which, being rather small compared with the corresponding $h_{1}$, 


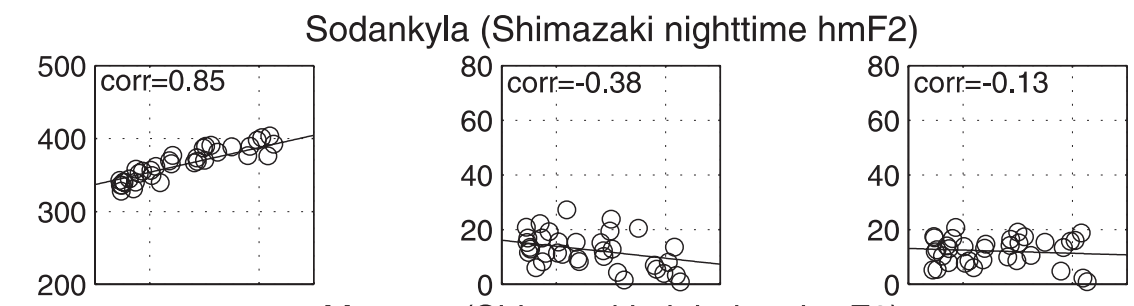

Moscow (Shimazaki nighttime hmF2)
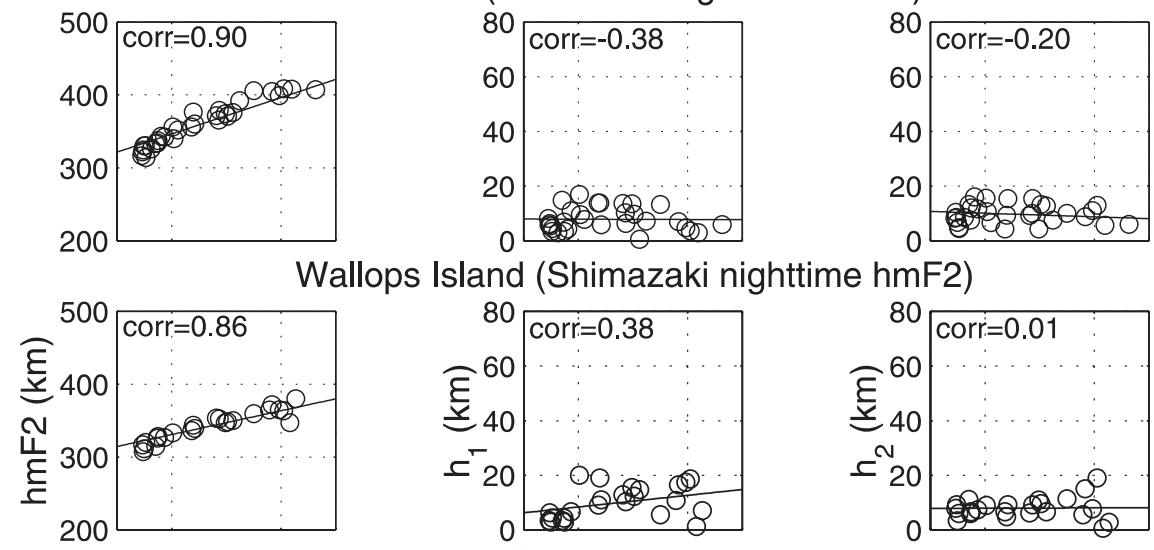

Wakkanai (Shimazaki nighttime hmF2)
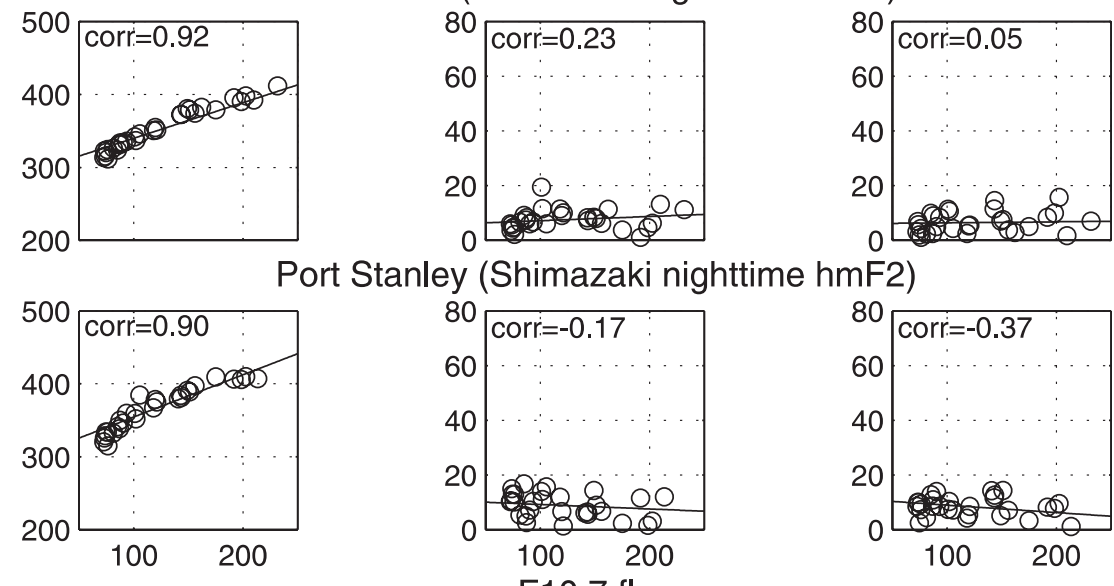

Port Stanley (Shimazaki nighttime hmF2)

b
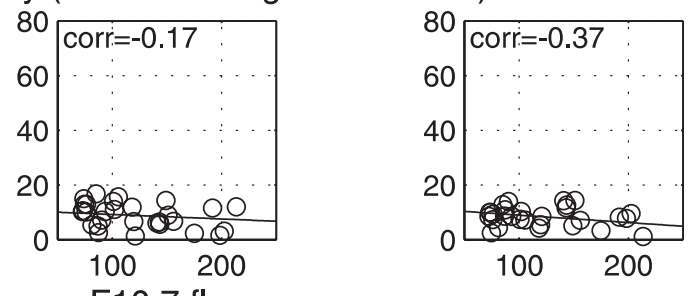

Fig. 5b

F10.7 flux

are not well determined by the analysis, nor are the derived phases $\phi_{2}$ trustworthy. The important conclusions are that the CTIP and TIME-GCM results for $h \mathrm{mF} 2$ agree quite well, and that the semiannual components are much smaller than are found in the ionosonde data.

\section{Semiannual variations in MSIS}

According to Rishbeth and Edwards (1989), the F2peak at a given local time should lie approximately at a constant pressure-level, for all seasons and all levels of solar activity. For midlatitude stations generally, these fixed pressure-levels are $20 \mu \mathrm{Pa}$ at noon and $2 \mu \mathrm{Pa}$ at midnight. We can test this assertion against the wellknown MSIS (Mass Spectrometer/Incoherent Scatter) model, which is widely used to represent the behaviour of thermospheric parameters. To do this, we examine how the heights $h_{\mathrm{PD}}$ and $h_{\mathrm{PN}}$ of the daytime and nighttime levels, defined by the pressure values just quoted, vary with season and solar activity, and compare them with the ionosonde values of $h \mathrm{mF} 2$. For this purpose we use the extended version MSISE-90 of Hedin (1991), although, since we consider only Fregion heights between about 200 and $450 \mathrm{~km}$, the extension below $90 \mathrm{~km}$ is not relevant to our study and for simplicity we use the term MSIS. As the nighttime TIME-GCM data used in Sect. 3.1 are for 02 LT instead of 00 LT (midnight), we use 02 LT for the MSIS study, which should make no significant difference.

\subsection{Quiet-day MSIS data}

We ran the MSIS model for the stations shown in Figs. 4 and 5, namely Sodankylä, Slough, Wakkanai, Wallops Island and Port Stanley. As the MSIS parameters vary 

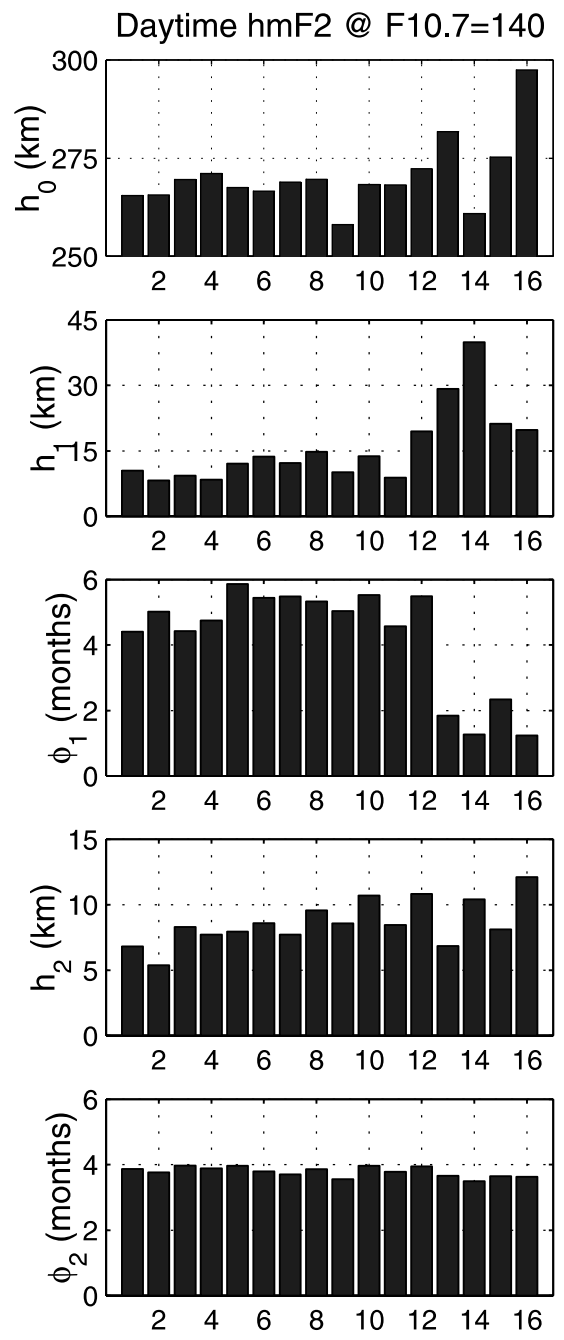

Nighttime hmF2 @ F10.7=140
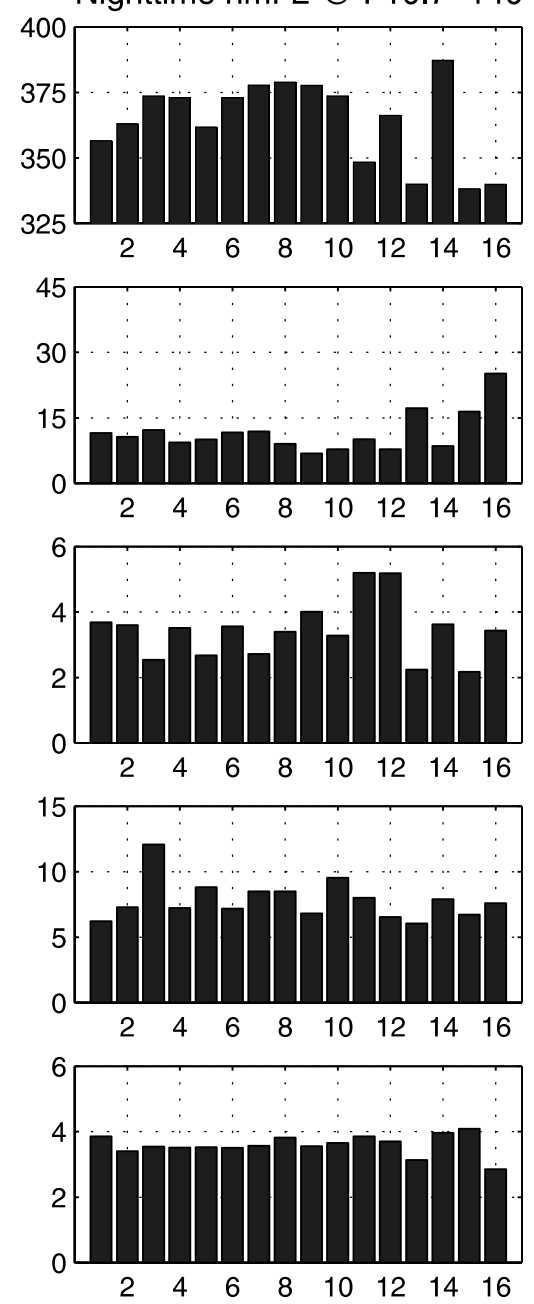

Fig. 6. Day and night values of annual mean $h \mathrm{mF} 2\left(h_{0}\right)$ and the amplitude and phase of the annual component $\left(h_{1}, \phi_{1}\right)$ and semiannual component $\left(h_{2}, \phi_{2}\right)$ for day $(10$ 14 LT) and night (22-02 LT), solar 10.7 flux 140 units. The stations are arranged in north-to-south order of magnetic latitude (1, Kiruna, 2, Loparskaya, 3, Sodankylä, 4, Lycksele, 5, Arkhangelsk, 6, Uppsala, 7, Leningrad, 8, Juliusruh, 9, Slough, 10, Moscow, 11, Wallops Is, 12, Wakkanai, 13, Norfolk Is, 14, Port Stanley, 15, Mundaring, 16, Kerguelen)

only slowly with latitude and longitude, the choice of locations is not critical, and it seemed unnecessary to do the calculations for all sixteen stations. We use the same two local times, $12 \mathrm{LT}$ and $02 \mathrm{LT}$, and three levels of solar activity, $F_{10.7}=70,140$ and 200 . To test the effect of geomagnetic activity, we use two different conditions: "quiet", for which we take $A \mathrm{p}=3$; and "average", for which we take $A \mathrm{p}=13,17$ and 20 to represent average conditions for the three levels of $F_{10.7}$. We further discuss the effect of varying $A \mathrm{p}$ in Sect. 4.2.

In Fig. 7a for day and $7 \mathrm{~b}$ for night, the MSIS pressure-level heights $h_{\mathrm{PD}}$ and $h_{\mathrm{PN}}$ are plotted against $F_{10.7}$, with circles denoting quiet and crosses denoting average magnetic conditions. Some numerical data are shown in Table 3 . The annual mean values of $h_{\mathrm{PD}}$ and $h_{\mathrm{PN}}$ (tabulated for $\left.F_{10.7}=140\right)$ agree quite well with hmF2 (Table 1a, b). They do not vary much between stations, and neither do their rates of change with solar activity, which are $\mathrm{d} h_{\mathrm{PD}} / \mathrm{d} F_{10.7} \approx 0.6 \mathrm{~km} /$ unit and $\mathrm{d} h_{\mathrm{PN}} /$ $\mathrm{d} F_{10.7} \approx 0.9 \mathrm{~km} /$ unit (averaged over the range $F_{10.7}=70$ to 200). There is some difference between day and night in that, as $F_{10.7}$ increases, the slope $\mathrm{d} h_{\mathrm{PD}} / \mathrm{d} F_{10.7}$ increases slightly while $\mathrm{d} h_{\mathrm{PN}} / \mathrm{d} F_{10.7}$ decreases, but these tendencies are too small to be easily seen in Fig. 7a, b.
The mean temperatures $T$ at these pressure-levels, also shown in Table 3, vary from place to place, though not in the same way as the pressure-level heights, which depend on composition as well as on temperature. The mean rates of increase of temperature with $F_{10.7}$ are similar at all stations, about $3.7 \mathrm{~K} /$ unit for day and $2.9 \mathrm{~K} /$ unit for night, both decreasing with increasing $F_{10.7}$.

The phases of the semiannual variations of $h_{\mathrm{PD}}$ and $h_{\mathrm{PN}}$ are very consistent, namely 3.9 months, which corresponds to a maximum about 1 month after equinox. By day, the maximum of the annual component occurs near summer solstice, the phases being 6.0 months at the northern stations and 0.3 month at Port Stanley, though at night the annual phases are not consistent between stations.

The semiannual variations in MSIS agree very well in phase, and broadly agree in amplitude, with those derived from the ionosonde data (Table 1a, b). The annual variations disagree: in particular, the remarkably small daytime amplitudes at Wallops Island and Wakkanai have no counterpart in the ionosonde data (Table 1a) nor in the TIME-GCM simulations (Table 2). The nighttime MSIS amplitude at Sodankylä 
Table 3. Temperatures $(T)$, and the heights $\left(h_{\mathrm{P}}\right)$ and annual and semiannual variations of fixed pressure-levels derived from MSISE-90. The two bottom lines in each part of the Table show the variations with $F_{10.7}$ (not shown for the annual component because they vary considerably between stations). See text regarding phases

\begin{tabular}{|c|c|c|c|c|c|c|}
\hline \multirow[t]{2}{*}{ Station } & \multirow{2}{*}{$\begin{array}{l}\text { Geographic } \\
\text { latitude }\end{array}$} & \multicolumn{2}{|c|}{ Annual mean } & \multicolumn{2}{|c|}{ Amplitude } & \multirow{2}{*}{$\begin{array}{l}\mathrm{d} h_{\mathrm{P}} / \mathrm{d} F_{10.7} \\
(200-70)(\mathrm{km} / \mathrm{unit})\end{array}$} \\
\hline & & $T(\mathrm{~K})$ & $h_{\mathrm{P}}(\mathrm{km})$ & $h_{1}(\mathrm{~km})$ & $h_{2}(\mathrm{~km})$ & \\
\hline Sodankylä & $67 \mathrm{~N}$ & 1005 & 274 & 5 & 7 & 0.61 \\
\hline Slough & $52 \mathrm{~N}$ & 1036 & 277 & 4 & 7 & 0.64 \\
\hline Wakkanai & $45 \mathrm{~N}$ & 1058 & 278 & 1 & 7 & 0.63 \\
\hline Wallops Is & $38 \mathrm{~N}$ & 1062 & 277 & 0.2 & 7 & 0.67 \\
\hline \multicolumn{7}{|l|}{ Differences } \\
\hline$F_{10.7}:(140-70)$ & & 284 & 42 & - & 1.8 & \\
\hline$F_{10.7}:(200-140)$ & & 200 & 38 & - & 1.7 & \\
\hline \multicolumn{7}{|c|}{$2 \mu \mathrm{Pa}$ at $02 \mathrm{LT}\left(h_{\mathrm{PN}}\right)\left(F_{10.7}=140, A \mathrm{p}=3\right)$} \\
\hline Sodankylä & $67 \mathrm{~N}$ & 938 & 370 & 3 & 11 & 0.92 \\
\hline \multicolumn{7}{|l|}{ Differences } \\
\hline$F_{10.7}:(140-70)$ & & 231 & 64 & - & 1.8 & \\
\hline$F_{10.7}:(200-140)$ & & 148 & 50 & - & 1.6 & \\
\hline
\end{tabular}

is also small. Another obvious discrepancy is that the MSIS heights $h_{\mathrm{PD}}$ and $h_{\mathrm{PN}}$ increase more rapidly with increasing $F_{10.7}$ than do the F2-layer mean heights $h_{0}$.

\subsection{How geomagnetic activity affects the annual and semiannual variations of pressure-levels}

We now discuss the effect of geomagnetic activity, which peaks at the equinoxes (Fig. 1). Magnetic activity increases thermosphere temperature and density, so it raises the heights of fixed pressure-levels. Thus the seasonal variations of magnetic activity affect the annual and semiannual variations of $h \mathrm{mF} 2$. We cannot directly investigate this effect in our ionosonde data, because that would entail separating "quiet" and "disturbed" days, which would seriously reduce the quantity of usable $h \mathrm{mF} 2$ data. Nor do the TIME-GCM and CTIP simulations described in Sect. 3 shed any light on the matter, because they assume quiet conditions with low $A$ p. We can, however, estimate the "geomagnetic effect", i.e. how much the fixed pressure-levels $h_{\mathrm{PD}}$ and $h_{\mathrm{PN}}$ are raised when average levels of magnetic activity are put into the MSIS model.

For this purpose we use monthly mean values of $A \mathrm{p}$ derived by M. Mendillo and colleagues (private communication, 1998) from geomagnetic data for 19551995, extracted from the CD-ROM produced by World Data Centre A for Solar-Terrestrial Physics. Three groups of years were defined according to the annual mean values of $F_{10.7}$, namely low $\left(F_{10.7}<80\right)$, medium $\left(140<F_{10.7}<155\right)$ and high $\left(F_{10.7}>175\right)$, with mean values of $A \mathrm{p}$ for "quiet" and "average" conditions as mentioned in Sect. 4.1. These groups correspond well to the levels $F_{10.7}=70,140,200$ used for the MSIS runs.

We ran MSIS with the "average" values of $A \mathrm{p}$, and compared the heights $h_{\mathrm{PD}}$ and $h_{\mathrm{PN}}$ with those obtained from the "quiet" runs $(A \mathrm{p}=3)$. This enabled us to obtain the rates of change $\mathrm{d} h_{\mathrm{PD}} / \mathrm{d} A \mathrm{p}$ for day $(0.4$ $0.7 \mathrm{~km} / \mathrm{unit})$, and $\mathrm{d} h_{\mathrm{PN}} / \mathrm{d} A \mathrm{p}$ for night $(0.7-1.3 \mathrm{~km} / \mathrm{unit})$, as shown in Table 4. We now apply these results to annual and semiannual variations, making the simplifying assumption that $h_{\mathrm{PD}}$ and $h_{\mathrm{PN}}$ vary linearly with $A \mathrm{p}$, which seems reasonable for the moderate values of $A \mathrm{p}$ involved. On average the temperature is $45 \mathrm{~K}$ higher at noon, and $63 \mathrm{~K}$ higher at night, for the "average" values of $A \mathrm{p}$ than for the "quiet" values.

For "medium" solar activity $\left(F_{10.7}=140\right)$, the semiannual variation of $A \mathrm{p}$ has amplitude $(A \mathrm{p})_{2}=2.5$ units and phase 4 months (maximum 1 month after equinox). The annual variation is smaller, with amplitude $(A \mathrm{p})_{1}=1.5$ units and phase also about 4 months. Because of its phase, the annual component of $A \mathrm{p}$ is small at the solstices, its effect being to increase $A \mathrm{p}$ at the March equinox and reduce it at the September equinox. (The amplitudes vary somewhat with $F_{10.7}$, and so does the annual phase; but we need not go into those details for our rough estimate of the geomagnetic effect.)

Combining the values of $\mathrm{d} h_{\mathrm{PD}} / \mathrm{d} A \mathrm{p}$ and $\mathrm{d} h_{\mathrm{PN}} / \mathrm{d} A \mathrm{p}$ with the amplitudes $(A \mathrm{p})_{1}$ and $(A \mathrm{p})_{2}$, we estimate the amplitude of the annual oscillations in $h_{\mathrm{PD}}$ and $h_{\mathrm{PN}}$ as shown in Table 4. The geomagnetic effect in the semiannual component is seen to be quite small, only $1-1.5 \mathrm{~km}$ by day and $2-3 \mathrm{~km}$ at night, and even smaller in the annual component. Comparing these with the semiannual amplitudes $h_{2}$ shown in Table 1, we conclude that the equinoctial peaks in geomagnetic activity 

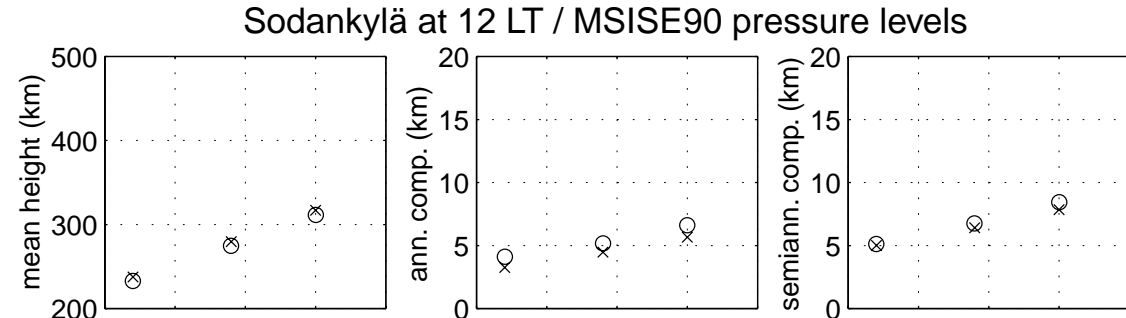

Moscow at $12 \mathrm{LT} / \mathrm{MSISE} 90$ pressure levels
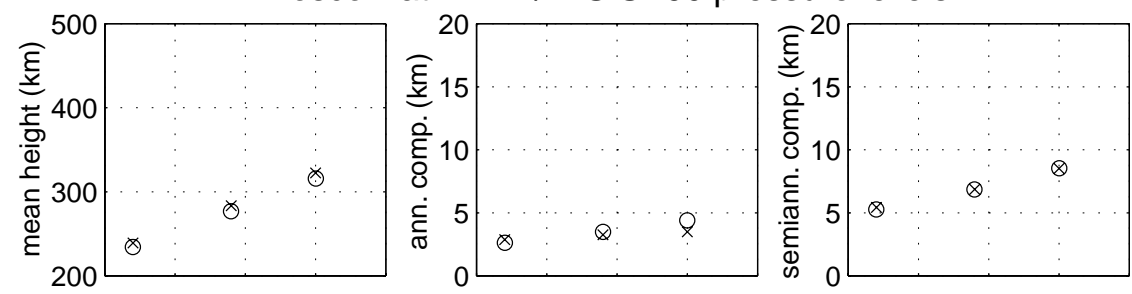

Wallops Is. at 12 LT / MSISE90 pressure levels
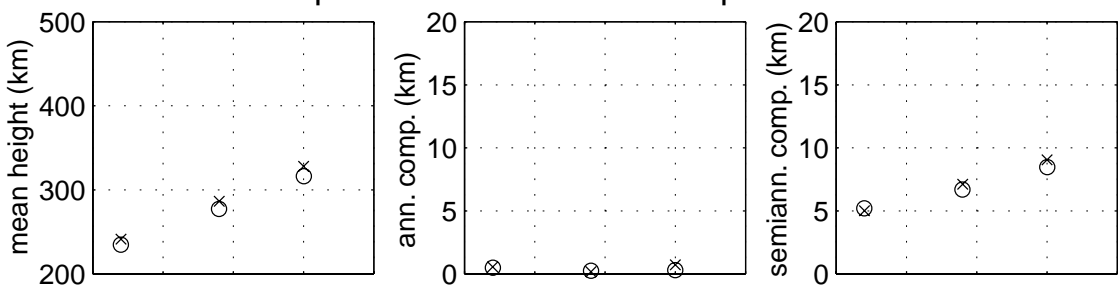

Wakkanai at $12 \mathrm{LT}$ / MSISE90 pressure levels
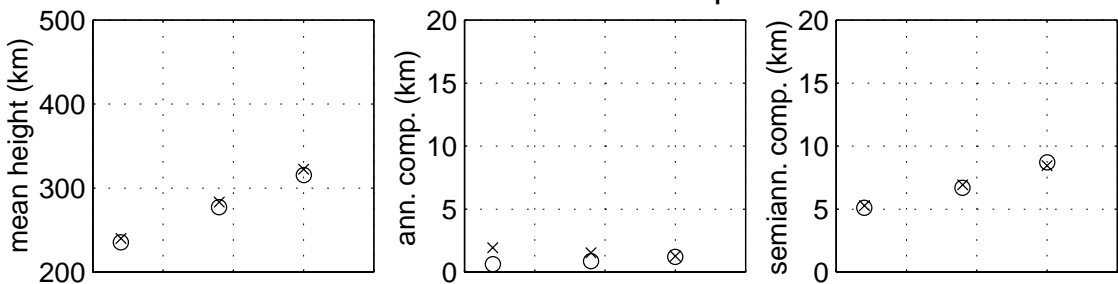

Port Stanley at 12 LT / MSISE90 pressure levels
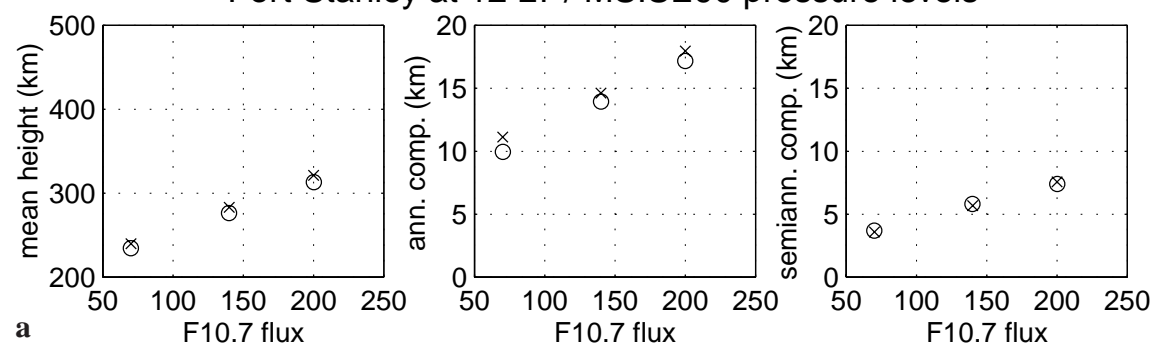

Fig. 7. a Annual means, annual and semiannual amplitudes of the fixed pressure-level $20 \mu \mathrm{Pa}$ (approximately corresponding to daytime $h \mathrm{mF} 2)$ plotted versus $10.7 \mathrm{~cm}$ solar flux at five stations for noon (12 LT). b Annual means, annual and semiannual amplitudes of the fixed pressure-level $2 \mu \mathrm{Pa}$ (approximately corresponding to nighttime $h \mathrm{mF} 2$ ) plotted versus $10.7 \mathrm{~cm}$ solar flux at five stations for night (02 LT) cause only a minor part of the semiannual variation in $h \mathrm{mF} 2$. A similar conclusion may be drawn from the Millstone Hill data of Papagiannis et al. (1975) discussed in Sect. 2.5.

\section{Discussion}

The ionosonde data show that the semiannual variation in $h \mathrm{mF} 2$ is real. Its phase is consistent, with maxima shortly after equinox, and its amplitude increases with increasing $F_{10.7}$. At high $F_{10.7}$ the semiannual component is roughly equal to the annual component, which is fairly constant in phase (maximum in summer, minimum in winter), becoming earlier with increasing $F_{10.7}$.
The combination of the annual and semiannual components generally leads to a maximum of $h \mathrm{mF} 2$ in April or May in the north, and January or February in the south.

The southern stations (Port Stanley, particularly) and also Wakkanai show strong annual variations of $h \mathrm{mF} 2$ by day, which may be attributed to the seasonal variations of meridional winds. Wind effects are particularly strong at Port Stanley and Wakkanai, which are situated in longitudes remote from the magnetic poles (Rishbeth, 1998). At Port Stanley, the effect of strong diurnally varying winds is seen in the annual mean $h_{0}$; the night value of $387 \mathrm{~km}$ is the highest, and the day value of $261 \mathrm{~km}$ the second lowest, of any of the 16 stations. Furthermore, the magnetic dip angle $I$ is close 


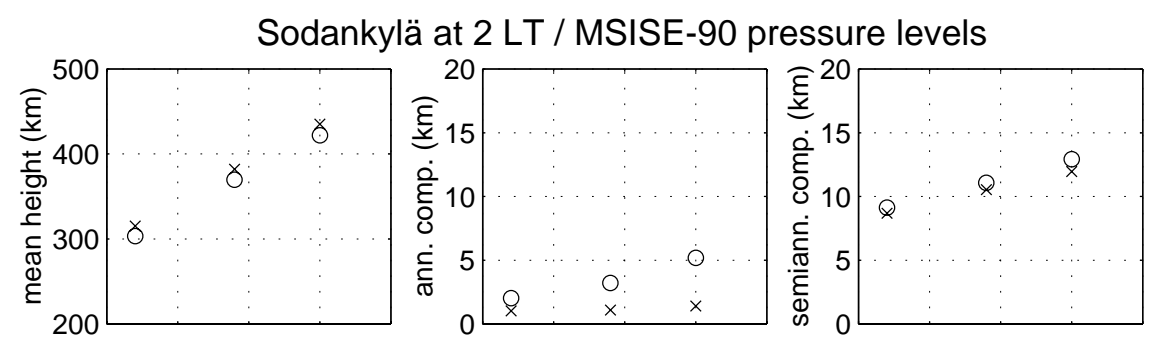

Moscow at 2 LT / MSISE-90 pressure levels

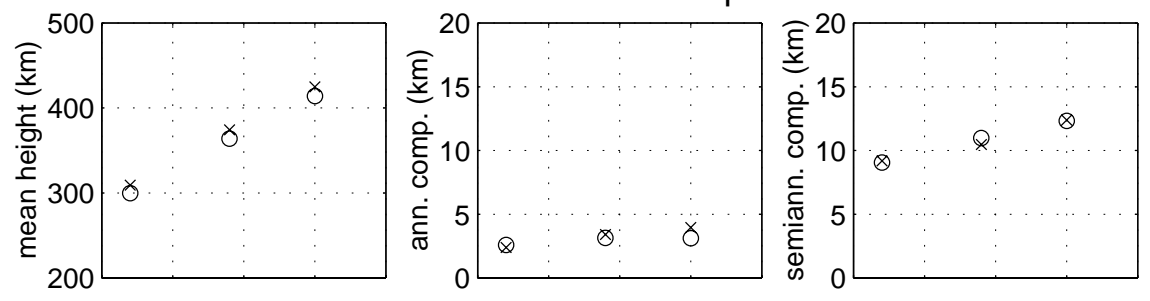

Wallops Is. at 2 LT / MSISE-90 pressure levels

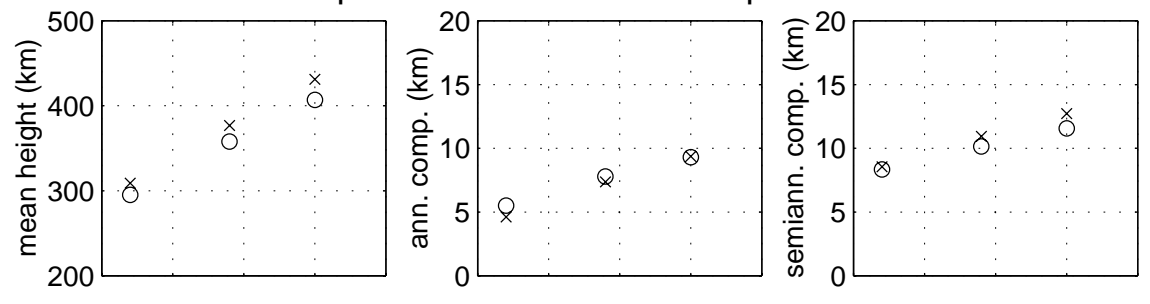

Wakkanai at 2 LT / MSISE-90 pressure levels

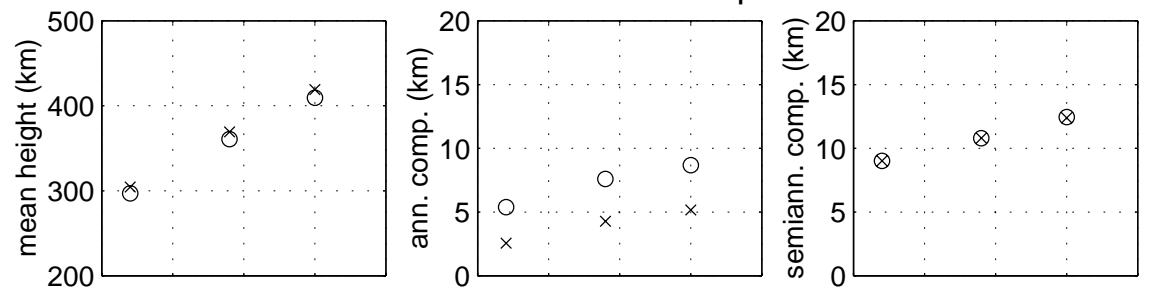

Port Stanley at 2 LT / MSISE-90 pressure levels
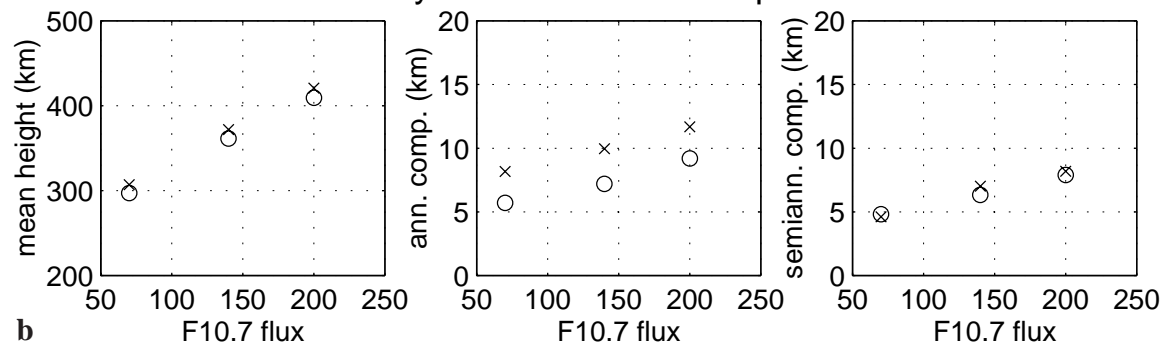

Fig. $7 b$

Table 4. Geomagnetic effect on the annual and semiannual variations of the heights of fixed pressure-levels $\left(h_{\mathrm{PD}}\right.$ and $\left.h_{\mathrm{PN}}\right)$ in the MSIS model, $F_{10.7}=140$, assuming the annual amplitude of $A \mathrm{p}$ to be $(A \mathrm{p})_{1}=1.5$ and the semiannual amplitude to be $(A \mathrm{p})_{2}=2.5$, as described in Sect. 4.2

\begin{tabular}{lllll}
\hline Station & $\begin{array}{l}\text { Geographic } \\
\text { latitude }\end{array}$ & $\begin{array}{l}\mathrm{d} h_{\mathrm{P}} / \mathrm{d} A \mathrm{p} \\
(\mathrm{km} / \mathrm{uni})\end{array}$ & $\begin{array}{l}h_{\mathrm{P}} \text { (annual) } \\
(\mathrm{km})\end{array}$ & $\begin{array}{l}h_{\mathrm{P}} \text { (semiannual) } \\
(\mathrm{km})\end{array}$ \\
\hline 12 LT Pressure-level $\left(h_{\mathrm{PD})}\right.$ & & & & \\
$\quad$ Sodankylä & $67 \mathrm{~N}$ & 0.4 & 0.6 & 1.0 \\
Slough & $52 \mathrm{~N}$ & 0.7 & 1.1 & 1.8 \\
Wakkanai & $45 \mathrm{~N}$ & 0.6 & 0.9 & 1.5 \\
Wallops Is & $38 \mathrm{~N}$ & 0.6 & 0.9 & 1.5 \\
Port Stanley & $52 \mathrm{~S}$ & 0.7 & 1.1 & 1.8 \\
02 LT Pressure-level $\left(h_{\mathrm{PN}}\right)$ & & & & \\
Sodankylä & $67 \mathrm{~N}$ & 0.7 & 1.0 & 1.7 \\
Slough & $52 \mathrm{~N}$ & 1.2 & 1.8 & 3.0 \\
Wakkanai & $45 \mathrm{~N}$ & 0.9 & 1.4 & 3.3 \\
Wallops Is & $38 \mathrm{~N}$ & 1.3 & 1.9 & 2.5 \\
Port Stanley & $52 \mathrm{~S}$ & 1.0 & 1.5 & \\
\hline
\end{tabular}


to the value of $45^{\circ}$ that maximizes the factor $\sin I \cos I$ (the vertical ion drift caused by a meridional wind $U$ being given by $U \sin I \cos I$ ).

The annual mean of $h \mathrm{mF} 2$ increases with solar activity, on average by $0.45 \mathrm{~km}$ per unit of the flux $F_{10.7}$. The variation is not precisely linear, and is slower than the rise of constant pressure-levels with increasing $F_{10.7}$ as given by the MSIS model, about $0.6 \mathrm{~km} / \mathrm{unit}$ at noon and $0.9 \mathrm{~km} /$ unit at night (Sect. 4.1). Over the range $F_{10.7}=70$ to 200 , the discrepancy amounts to about $20 \mathrm{~km}$ by day and $60 \mathrm{~km}$ at night. This means that, as solar activity increases, $h \mathrm{mF} 2$ is not accurately "isobaric", it does not precisely follow constant pressure-levels. As shown by Rishbeth and Edwards (1989), $h \mathrm{mF} 2$ is strongly influenced by meridional winds. As these winds vary with solar cycle, they may be the cause of the discrepancy between $h \mathrm{mF} 2$ and the pressure-level heights.

We find no relation between the semiannual variations of $h \mathrm{mF} 2$ and the well-known variations of noon $N \mathrm{mF} 2$. For example, Port Stanley has a mainly annual (summer/winter) variation of $h \mathrm{mF} 2$ and a strongly semiannual variation of $N \mathrm{mF} 2$. Northern stations like Slough, Moscow and Wallops Island have a predominantly annual (summer/winter) variation of $N \mathrm{mF} 2$, but their annual and semiannual variations of $h \mathrm{mF} 2$ are comparable in amplitude. These are particular examples of the more general situation shown in the maps of Torr and Torr (1973), namely, that noon $N \mathrm{mF} 2$ at midlatitudes has a predominantly seasonal (winter/summer) variation in longitudes close to the magnetic poles, but elsewhere the variation is predominantly semiannual. This difference in behaviour is reproduced by CTIP (Millward et al., 1996b; Rishbeth, 1998). For hmF2, we found that the largest summer/winter variations occur in southern latitudes, most notably at Port Stanley, where the thermospheric wind effects are particularly strong.

Several theories exist as to the origin of the F2-layer semiannual variation. In order from the Sun outwards, they include:

1. A hypothesis that the Sun's EUV radiation varies with heliographic latitude (Burkard, 1951), combined with the semiannual variation of the Earth's heliographic latitude;

2. The known semiannual variation in geomagnetic activity, which is attributed to geometrical effects, such as the variation of solar wind parameters with heliographic latitude and the geometry of solar wind/ magnetosphere coupling;

3. Semiannual changes of temperature and composition generated internally within the thermosphere by dynamical and chemical processes;

4. Possible semiannual variations in influences transmitted to the thermosphere from the underlying mesosphere, such as tides and waves of various kinds.

Dismissing (1) because of the lack of any supporting evidence, we tested (2) as described in Sect. 4.2, and found that the semiannual variation of magnetic activity accounts for less than half the semiannual variation of midlatitude $h \mathrm{mF} 2$. In this analysis we took the $A \mathrm{p}$ index to represent the geomagnetic effect, and used MSIS to model the variation with $A \mathrm{p}$ of thermospheric temperature and pressure. So our conclusion depends on how well MSIS represents the geomagnetically disturbed thermosphere. One mechanism that might provide the link between geomagnetic activity and the global semiannual temperature variation is the "conduction mode" oscillation of the thermosphere (Walterscheid, 1982), which is forced by the semiannually varying Joule heating at high latitudes and is thus related to the $A \mathrm{p}$ index, at least in principle. Chaman Lal $(1992,1998)$ postulates some additional solar wind influence on the thermosphere, apparently in addition to that which is represented by indices such as $A \mathrm{p}$, but its physical mechanism is not clear.

As for (3): the TIME-GCM and CTIP models take account of the internal processes in the thermosphere, driven by solar ionizing radiation and the quiet-day energy inputs from the magnetosphere and solar wind. Despite their success in reproducing both seasonal and semiannual variations of $\mathrm{NmF} 2$, these models, at least in the versions used here, do not reproduce the semiannual variations in quiet-day $h \mathrm{mF} 2$ (Sect. 3). The rough estimates made in Sect. 4.2 suggests that, even if the semiannual geomagnetic variation were included in these models, this conclusion would not change. Nor do we think it would change if we used real height $N(h)$ analysis instead of the MUF-based formula for calculating $h \mathrm{mF} 2$ (Sect. 2.3).

There remain tidal and wave inputs from the mesosphere and lower levels (4) which, together with (2), seem the best available explanation of the equinox maxima in $h \mathrm{mF} 2$. The tidal input to the thermosphere is estimated as $10^{10} \mathrm{~W}$, as compared to the solar EUV input of order $10^{13} \mathrm{~W}$, but if this tidal input is modulated semiannually, it may explain the semiannual variations of thermospheric temperature and thus of hmF2 (A. S. Rodger, private communication, 1998). Gravity wave inputs (e.g. Reid, 1986) also need to be considered.

\section{Conclusions}

At middle and low latitudes, we find that $h \mathrm{mF} 2$ has a well-defined relationship with solar activity, a clear annual variation (high in summer, low in winter), and a clear semiannual variation (high at equinox, low at solstice), comparable in amplitude to the annual variation. The semiannual variation of $h \mathrm{mF} 2$ is not related to that of $N \mathrm{mF} 2$, and is not reproduced by computational models of the quiet-day thermosphere and ionosphere (Sect. 3). Although our analysis uses both computational models (TIME-GCM and CTIP) and an empirical model (MSIS) to interpret the ionosonde data, we believe we have done this in a valid way.

Theory predicts that the height $h \mathrm{mF} 2$ depends on thermospheric density and temperature, so is affected by the semiannual variation in thermospheric density. On the assumption that $h \mathrm{mF} 2$ follows levels of constant atmospheric pressure (different for day and night), we find reasonably good agreement between the semiannual 
component in the ionosonde $h \mathrm{mF} 2$ data and in the MSIS empirical mode (Sect. 4.1), and poor agreement in the annual component. The heights of the pressurelevels given by MSIS rise faster with increasing solar activity than do the values of $h \mathrm{mF} 2$. This discrepancy may be due to variations in meridional thermospheric winds.

Although $h \mathrm{mF} 2$ is affected by geomagnetic activity, which heats the thermosphere and thus raises the height of fixed pressure-levels, this accounts for only a small part of the observed semiannual variation of $h \mathrm{mF} 2$ (Sect. 4.2). For lack of another explanation, we suggest that the remainder is due to semiannually varying input of wave and tidal energy from lower levels in the atmosphere.

Acknowledgements. We gratefully acknowledge the generosity of R. G. Roble for providing outputs from a one year's run of TIMEGCM. Thanks are due to R. Whitfield of Verwood, U.K., who performed some of the data analysis, and to M. Mendillo, J. Wroten and E. Damboise of Boston University for providing seasonal variations of $A \mathrm{p}$ and for preparing the $h \mathrm{mF} 2$ data from the TIME-GCM run. We thank J. R. Dudeney for helpful advice on the use of the MUF parameter, M. H. Rees and A. S. Rodger for useful discussions, and the referees for their helpful comments. The TIME-GCM computational model is supported by the US National Oceanic and Atmospheric Administration. CTIP is a joint collaborative project between the Atmospheric Physics Laboratory, University College London, the School of Mathematics and Statistics, University of Sheffield, and the NOAA Space Environment Centre, Boulder, Colorado. The CTIP modelling was supported by the UK Natural Environment Research Council under the Antarctic Special Topic programme AST-4 and used the CRAY-YMP system at the Rutherford Appleton Laboratory. The ionospheric data were obtained from the Vertical Sounding Database CD-ROM supplied by the National Geophysical Data Centre, Boulder, Colorado. We thank the countless people around the world who have maintained ionosondes and scaled the data.

Topical Editor M. Lester thanks M. Mendillo and another referee for their help in evaluating this paper.

\section{References}

Bartels, J., Discussion of time variations of geomagnetic activity, indices Kp and Ap 1932-1961, Ann. Geophysicae, 19, 1-20, 1963.

Becker, W., On the seasonal effect of the F-region at middle latitudes, in Electron density distribution in ionosphere and exosphere, Ed. E. Thrane, North-Holland, Amsterdam, 217221, 1964.

Becker, W., The temperature of the $\mathrm{F}$ region deduced from electron number density profiles, J. Geophys. Res., 72, 2001-2006, 1967.

Bilitza, D., N. M. Sheikh, and R. Eyfrig, A global model for the height of the F2-peak using M3000 values from the CCIR numerical map, Telecom. J., 46, 549-553, 1979.

Burkard, O., Die halbjährige Periode der F2-Schicht-Ionisation, Archiv Meteorol. Bioklim. Wien 4, 391-402, 1951.

Chaman Lal, Global F2 layer ionization and geomagnetic activity, J. Geophys. Res., 97, 12 153-12 159, 1992.

Chaman Lal, Solar wind and equinoctial maxima in geophysical phenomena, J. Atmos. Solar-Terr. Phys., 60, 1017-1024, 1998.

Dudeney, J. R., The accuracy of simple methods for determining the height of the maximum electron concentration of the F2layer from scaled characteristics, J. Atmos. Terr. Phys., 45, 629-640, 1983.
Eccles D., J. W. King, R. Pratt, and H. Kohl, The semi-annual variation in the height of the F2-layer peak, J. Atmos. Terr. Phys., 29, 1641-1646, 1967.

Fuller-Rowell, T. J., D. Rees, S. Quegan, R. J. Moffett, M. V. Codrescu, and G. H. Millward, A coupled thermosphereionosphere model (CTIM), in STEP handbook of ionospheric models, Ed. R. W. Schunk, Utah State University, Logan, Utah, 217-238, 1996.

Green, C. A., The semiannual variation in the magnetic activity indices Aa and Ap, Planet. Space Sci., 32, 297-305, 1984.

Hedin, A. E., Extension of the MSIS thermospheric model into the middle and lower atmosphere, J. Geophys. Res., 96, 1159-1172, 1991.

McNamara, L. F., B. W. Reinisch, and J. S. Tang, Values of $h \mathrm{mF} 2$ deduced from automatically scaled ionograms, $A d v$. Space Res., 7(6), 53-56, 1987.

Millward, G. H., R. J. Moffett, S. Quegan, and T. J. Fuller-Rowell, A coupled thermosphere-ionosphere-plasmasphere model (CTIP), in STEP handbook of ionospheric models, Ed. R. W. Schunk, Utah State University, Logan, Utah, 239-280, 1996a.

Millward, G. H., H. Rishbeth, T. J. Fuller-Rowell, A. D. Aylward, S. Quegan, and R. J. Moffett, Ionospheric F2 layer seasonal and semiannual variations, J. Geophys. Res., 101, 5149-5156, $1996 \mathrm{~b}$.

Paetzold, H. K., and H. Zschörner, An annual and a semiannual variation of the upper air density, Geofis. Pura Appl., 48, 85-92, 1961.

Papagiannis, M. D., H. Hassan-Hosseinieh, and M. Mendillo, Changes in the ionospheric profile and the Faraday factor $M$ with Kp, Planet. Space Sci., 23, 107-113, 1975.

Rawer, K., Synoptic ionospheric observations, including absorption, drifts and special programmes, Ann. IQSY, 5, 97-130, 1969.

Reid, I. M., Gravity wave motions in the upper middle atmosphere (60-110 km), J. Atmos. Terr. Phys., 48, 1057-1072, 1986.

Rishbeth, H., How the thermospheric circulation affects the ionospheric F2-layer, J. Atmos. Terr. Phys., 60, 1385-1402, 1998.

Rishbeth, H., and R. Edwards, The isobaric F2-layer, J. Atmos. Terr. Phys., 53, 321-338, 1989.

Roble, R. G., E. C. Ridley, A. D. Richmond, and R. E. Dickinson, A coupled thermosphere/ionosphere general circulation model, Geophys. Res. Lett., 15, 1325-1328, 1988.

Shimazaki, T., World-wide variations in the height of the maximum electron density of the ionospheric F2 layer, J. Radio Res. Labs. 2(7), 85-97, 1955.

Titheridge, J. E., Single-polynomial analysis of ionograms, Radio Sci., 4, 41-51, 1969.

Torr, M. R., and D. G. Torr, The seasonal behaviour of the F2layer of the ionosphere, J. Atmos. Terr. Phys., 35, 2237-2251, 1973.

Ulich, T., and E. Turunen, Evidence for long-term cooling of the upper atmosphere in ionosonde data, Geophys. Res. Lett., 24, 1103-1106, 1997.

Walterscheid, R. L., The semiannual oscillation in the thermosphere as a conduction mode, J. Geophys. Res., 87, 1052710535,1982

Yonezawa, T., The solar-activity and latitudinal characteristics of the seasonal, non-seasonal and semi-annual variations in the peak electron densities of the F2-layer at noon and at midnight in middle and low latitudes, J. Atmos. Terr. Phys., 33, 889-907, 1971.

Yonezawa, T., and Y. Arima, On the seasonal and non-seasonal annual variations and the semi-annual variation in the noon and midnight electron densities of the F2 layer in middle latitudes, J. Radio Res. Labs., 6, 293-309, 1959.

Zou, L., H. Rishbeth, I. C. F. Müller-Wodarg, A. D. Aylward, G. H. Millward, T. J. Fuller-Rowell, D. W. Idenden, and R. J. Moffett, Annual and semiannual variations in the ionospheric F2-layer. 1: A modelling study, Ann. Geophysicae, in press, 2000. 